\title{
Article \\ An Open Access Chamber Designed for the Acoustic Characterisation of Microbubbles
}

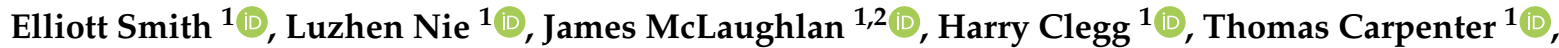 \\ David Cowell $^{1}{ }^{1}$, Stephen Evans ${ }^{3} \mathbb{C}^{-}$, Alejandro F. Frangi ${ }^{4,5,6} \mathbb{C}^{-}$and Steven Freear ${ }^{1, * \mathbb{C}}$
}

1 School of Electronic and Electrical Engineering, University of Leeds, Leeds LS2 9JT, UK; e.i.j.smith@leeds.ac.uk (E.S.); 1.nie@leeds.ac.uk (L.N.); j.r.mclaughlan@leeds.ac.uk (J.M.); h.r.clegg1@leeds.ac.uk (H.C.); t.carpenter@leeds.ac.uk (T.C.); d.m.j.cowell@leeds.ac.uk (D.C.)

2 Leeds Institute of Medical Research, Wellcome Trust Brenner Building, St James's University Hospital, Leeds LS9 7TF, UK

3 Molecular and Nanoscale Physics Group, School of Physics and Astronomy, University of Leeds, Leeds LS2 9JT, UK; s.d.evans@leeds.ac.uk

4 Centre for Computational Imaging and Simulation Technologies in Biomedicine (CISTIB), School of Computing, University of Leeds, Leeds LS2 9JT, UK; a.frangi@leeds.ac.uk

5 Institute for Cardiovascular and Metabolic Medicine (LICAMM), School of Medicine, University of Leeds, Leeds LS2 9JT, UK

6 Alan Turing Institute, London NW1 2DB, UK

* Correspondence: s.freear@leeds.ac.uk

check for

updates

Citation: Smith, E.; Nie, L.;

McLaughlan, J.; Clegg, H.; Carpenter,

T.; Cowell, D.; Evans, S.; Frangi, A.F.; Freear, S. An Open Access Chamber Designed for the Acoustic Characterisation of Microbubbles. Appl. Sci. 2022, 12, 1818. https:// doi.org/10.3390/app12041818

Academic Editor: Giuseppe Lacidogna

Received: 22 December 2021

Accepted: 31 January 2022

Published: 10 February 2022

Publisher's Note: MDPI stays neutral with regard to jurisdictional claims in published maps and institutional affiliations.

Copyright: (c) 2022 by the authors. Licensee MDPI, Basel, Switzerland. This article is an open access article distributed under the terms and conditions of the Creative Commons Attribution (CC BY) license (https:// creativecommons.org/licenses/by/ $4.0 /)$.

\begin{abstract}
Microbubbles are used as contrast agents in clinical ultrasound for Left Ventricular Opacification (LVO) and perfusion imaging. They are also the subject of promising research in therapeutics as a drug delivery mechanism or for sonoporation and co-administration. For maximum efficacy in these applications, it is important to understand the acoustic characteristics of the administered microbubbles. Despite this, there is significant variation in the experimental procedures and equipment used to measure the acoustic properties of microbubble populations. A chamber was designed to facilitate acoustic characterisation experiments and was manufactured using additive manufacturing techniques. The design has been released to allow wider uptake in the research community. The efficacy of the chamber for acoustic characterisation has been explored with an experiment to measure the scattering of SonoVue ${ }^{\circledR}$ microbubbles at the fundamental frequency and second harmonic under interrogation from emissions in the frequency range of 1.6 to $6.4 \mathrm{MHz}$. The highest overall scattering values were measured at $1.6 \mathrm{MHz}$ and decreased as the frequency increased, a result which is in agreement with previously published measurements. Statistical analysis of the acoustic scattering measurements have been performed and a significant difference, at the $5 \%$ significance level, was found between the samples containing contrast agent and the control sample containing only deionised water. These findings validate the proposed design for measuring the acoustic scattering characteristics of ultrasound contrast agents.
\end{abstract}

Keywords: ultrasound; contrast agent; microbubble; acoustic characterisation; scattering; drug delivery

\section{Introduction}

Microbubbles are gas-filled bubbles encapsulated in a shell and are typically 1-10 $\mu \mathrm{m}$ in diameter. Microbubbles are used as Ultrasound Contrast Agents (UCAs) because they oscillate in the presence of an acoustic field. This oscillation is due to the stiffness of the enclosed gas and the inertia of the liquid surrounding the microbubble [1,2]. Microbubbles act as resonant systems during insonification [3]. The resonant frequency is dependent on the physical properties of the encapsulating shell, the gas core, and the surrounding medium $[2,4,5]$. An oscillating microbubble dissipates energy through re-radiation, viscous dissipation, and thermal dissipation $[3,6]$. 
The behaviour of single microbubbles can be extended to populations provided that the concentration is sufficiently small [1]. At low concentrations, multiple scattering and the interactions between oscillating microbubbles can be ignored. Thus, for a population, both scattering and attenuation can be measured acoustically. The total scattering measured is the summation of the scattering from individual microbubbles and the total attenuation measured is the summation of the scattering and absorption from individual microbubbles [2]. Because the microbubble radius is inversely proportional to the resonant frequency [2], the population size distribution has an impact on the acoustic response. By measuring the overall acoustic response of a microbubble population, as opposed to single microbubble measurements, the number of measurements required to obtain a result that is statistically significant is reduced [7]. This can reduce the time needed to perform the characterisation experiment.

A common clinical application for UCAs is in contrast-enhanced echocardiography for Left Ventricular Opacification (LVO) [8]. For this application, the contrast agent is required to generate strong backscattered signals in the presence of a pressure wave in the range of frequencies used for diagnostic cardiac ultrasound imaging. Typically, cardiac imaging has a frequency range of $2-8 \mathrm{MHz}$. The scattering power of oscillating microbubbles is the largest near to the resonant frequency. Another requirement for cardiac imaging is that microbubbles are sufficiently small (less than $8 \mu \mathrm{m}$ in diameter) to pass through the pulmonary microcirculation and stable enough to reach the left ventricle [4]. The use of gases with a high molecular weight and the encapsulation of microbubbles in a shell have improved the stability of UCAs. These advances also cause an increase in both resonant frequency and viscosity, which increases the damping [3]. Microbubbles less than $8 \mu \mathrm{m}$ in diameter have resonances within the range of frequencies of diagnostic ultrasound [9].

The acoustic properties of UCAs can induce imaging artefacts unique to contrastenhanced ultrasound imaging. In LVO, the concentration of microbubbles administered must be kept sufficiently low to limit the shadowing artefacts that can be introduced as a result of microbubble attenuation. At the Mechanical Index (MI) typically used in conventional echocardiography, destruction can occur by fragmentation of the microbubble or diffusion of the gas [10]. For most contrast-enhanced imaging applications, the MI is typically below 0.5 or, to limit microbubble destruction further and alleviate the swirling artefact, an MI lower than 0.2 may be used [8].

When driven at resonance, microbubble oscillation can be highly non-linear, resulting in the emission of sub-harmonics or harmonics of the incident frequency [11]. This nonlinear response can be exploited to improve the delineation of the endocardial border in contrast-enhanced echocardiography through contrast-specific imaging modalities. Secondharmonic imaging [12] and sub-harmonic imaging [13] are two such modalities that rely on separating the contrast signal from that of tissue based on frequency filtering. In pulse inversion imaging [14], two pulses of opposite polarity are emitted and are subsequently compounded in the receive beamformer. Amplitude modulation is another multi-pulse technique, which results in a similar cancellation of the linear echoes [15].

Contrast specific imaging modalities are exploited in perfusion imaging. A rapid succession of high pressure pulses can be transmitted to destroy the microbubbles in the region of interest. Destruction still occurs well within FDA guidelines that states for cardiac applications the MI should not exceed 1.9 [16]. By suppressing the tissue response, quantitative assessment of reperfusion is possible. It may be possible to further improve quantitative perfusion imaging by using a monodisperse population of microbubbles, with higher sensitivity and more control over the acoustic response [7]. To take full advantage of a monodisperse population for such applications, it is important to characterise the population acoustically and to tailor the insonification accordingly.

Stable cavitation and inertial cavitation can be exploited for therapeutics, either through attachment and delivery of a therapeutic agent [17] or through sonoporation of cells and co-administration of a therapeutic agent [18]. A number of mechanisms may contribute to sonoporation, including stable cavitation and micro-streaming [19]. When 
streaming occurs close to a cell membrane, shear stress created by the moving fluid causes pores to appear. During more violent inertial cavitation, jet formations can occur, which can cause large pores to appear in the cell membrane $[19,20]$. The microbubbles experience their maximum radial response at resonance. For sonoporation, this translates into more forces exerted on the surface of the cell [21]. Sonoporation efficiency may be increased by using a monodisperse population of microbubbles created through filtering of a polydisperse population [7] or directly formed using microfluidic flow focusing techniques [22]. Alternatively, the efficiency may be increased for a polydispersed population through a broadband excitation such as a linear-frequency-modulated pulse [23].

For delivery of a therapeutic agent, the agent can be attached to the shell in liposomal form [24] or can be contained in a thin oil layer in the microbubble [21]. The therapeutic agent can be released through inertial cavitation or through controlled lipid shedding [25]. Once again, exciting the microbubbles at the resonant frequency increases the efficiency of the payload delivery [21]. The changes in the shell parameters of the liposome-loaded microbubbles have been shown to alter their acoustic characteristics through optical [26] and acoustic measurements [27]. The addition of an oil layer in the shell also leads to changes in the microbubbles' acoustic characteristics [28]. Because the efficiency of the drug delivery is dependent on the insonification parameters, it is important to characterise these modified microbubbles when trialing their use for therapeutics applications.

Examples of acoustic characterisation experiments that have been performed previously are included in Table 1. Despite the clear benefit to both imaging and therapeutics applications, there is very little consistency in the experimental setup or protocol used to investigate the acoustic characteristics of microbubbles. Variations in the parameters of the transmitters and receivers, vessel geometry, and the interrogating acoustic wave can make comparison between different research groups challenging.

For attenuation measurements, the transmitter and receiver are usually placed in line with each other. A hydrophone is often used as the receiver to obtain the response from the sample over a broad range of frequencies [27,29]. An alternative approach uses the transmit transducer as the receiver and a strong reflector positioned behind the sample [4]. Scattering can be measured by the transmit transducer [30] or by another transducer, or hydrophone, placed in a position orthogonal to the transmit transducer $[27,29]$. In the case where the transmit transducer is used to measure backscatter, the limitations of the transducer bandwidth may prevent the measurement of sub-harmonics or second harmonics. Measurements are taken with deionised water to obtain a reference. Measurements are then taken with a known dilution of microbubbles. The experiment is usually performed with only one transmitter and one receiver, and the different acoustic measurements are normally taken separately $[27,29]$.

Generally, a sample vessel with acoustically transparent windows is used to constrain the solution of microbubbles in the far-field of the transmitter and receiver. The vessel dimensions used vary considerably. In [29], the volume of the vessel was $500 \mathrm{~mL}$, and in [27], the vessel had a total volume of $100 \mathrm{~mL}$. The dimensions of the vessel used is a trade-off between limiting the size of the microbubble sample required and minimising the interactions between the chamber walls and the ultrasound beam. The sample volume is made larger than the receiver beam-width to ensure as many microbubbles are measured in a single insonification as possible. In procedures using a needle hydrophone, the beamwidth is small and the sensitivity is low compared to a transducer. Only a small subset of the microbubbles in the sample vessel are in the path of the receiver and a large percentage of the sample goes unmeasured. A magnetic stirrer is used to keep the microbubbles uniformly distributed in the ultrasound beam during the experiment. The sample vessel must be refilled with a fresh sample regularly for new measurements and measurement repetitions. This can lead to the requirement of a large quantity of microbubbles to perform the complete acoustic characterisation. 
Table 1. Variability in the parameters of the transmitters, receivers, vessel geometry, and the interrogating acoustic waves found in examples of acoustic characterisation experiments.

\begin{tabular}{|c|c|c|c|c|c|c|}
\hline Measurement & Vessel & Transmitter & Transmission & Receiver & Microbubble & Ref. \\
\hline Attenuation & $\begin{array}{l}\text { Sample vessel with } \\
\text { acoustic path length } \\
\text { of } 60 \mathrm{~mm} \text { and a } 30 \\
\mu \mathrm{m} \text {-thick material } \\
\text { on the face oriented } \\
\text { at } 15^{\circ} \text { to the acoustic } \\
\text { axis of transducer. }\end{array}$ & $\begin{array}{l}\text { 1, } 2.25,5 \text {, and } 10 \\
\text { MHz transducers. } \\
\text { (Panametrics-NDT, } \\
\text { Waltham, MA, USA). } \\
\text { Focal length: } 75 \mathrm{~mm} \text {. }\end{array}$ & $\begin{array}{l}125 \mathrm{~ns} \text { pulse ( } 1 \text { and } \\
2.25 \mathrm{MHz} \text { transduc- } \\
\text { ers) or } 35 \mathrm{~ns} \text { pulse ( } 5 \\
\text { and } 10 \mathrm{MHz} \text { trans- } \\
\text { ducers). } \\
125 \mathrm{~ns} \text { pulse ( } 1 \text { and } \\
2.25 \mathrm{MHz} \text { transduc- } \\
\text { ers) or } 35 \mathrm{~ns} \text { pulse (5 } \\
\text { and } 10 \mathrm{MHz} \text { trans- } \\
\text { ducers). }\end{array}$ & $\begin{array}{l}\text { Transmitter used as } \\
\text { receiver (reflector } \\
\text { used behind sample } \\
\text { vessel). } \\
\text { Transmitter used as } \\
\text { receiver. }\end{array}$ & $\begin{array}{l}\text { Albunex }{ }^{\circledR} \text {. }(\text { Molec- } \\
\text { ular Biosystems, } \\
\text { Inc., San Diego, CA, } \\
\text { USA) }\end{array}$ & {$[30]$} \\
\hline Attenuation & $\begin{array}{l}3 \text { different sample } \\
\text { vessels with acoustic } \\
\text { path lengths of } 4 \text {, } \\
6 \text {, and } 8 \mathrm{~cm} ; 6 \mu \mathrm{m} \\
\text { acoustically transpar- } \\
\text { ent windows. }\end{array}$ & $\begin{array}{l}\text { 3.5 MHz transducer. } \\
\text { (V380 Panametrics- } \\
\text { NDT, Waltham, MA, } \\
\text { USA). Focused. }\end{array}$ & $\begin{array}{l}\text { Narrowband 4-cycle } \\
\text { Gaussian enveloped } \\
\text { sinusoidal pulses: } \\
\text { 1-5 MHz. Peak } \\
\text { negative pressure: } \\
\text { 10.6-106 kPa. } \\
\text { Narrowband 4-cycle } \\
\text { Gaussian enveloped } \\
\text { sinusoidal pulses: } \\
\text { 1-5 MHz. Peak neg- } \\
\text { ative pressures: } \\
\text { 10.6-106 kPa at } 1 \\
\text { MHz upto 50.5-505 } \\
\text { kPa at } 5 \mathrm{MHz} \text {. }\end{array}$ & $\begin{array}{l}\text { 3.5 MHz transducer. } \\
\text { (V380 Panametrics- } \\
\text { NDT, Waltham, MA, } \\
\text { USA). Focused. }\end{array}$ & $\begin{array}{l}\text { SonoVue }{ }^{\circledR} \text {. (Bracco } \\
\text { Research SA, } \\
\text { Geneva, Switzer- } \\
\text { land) }\end{array}$ & {$[31]$} \\
\hline Attenuation & $\begin{array}{l}500 \mathrm{~mL} \text { sample } \\
\text { vessel. } 6 \mu \mathrm{m} \text { acous- } \\
\text { tically transparent } \\
\text { windows. }\end{array}$ & $\begin{array}{l}\text { 3.5 MHz transducer. } \\
\text { (V380 Panametrics- } \\
\text { NDT, Waltham, MA, } \\
\text { USA). Focal length: } \\
75 \mathrm{~mm} .\end{array}$ & $\begin{array}{l}\text { 2-cycle Gaussian } \\
\text { pulse. Peak neg- } \\
\text { ative pressure: } \\
\text { 20-280 kPa. } \\
\text { 2-cycle Gaussian } \\
\text { pulse: } 4 \mathrm{MHz} \text { centre } \\
\text { frequency. Peak } \\
\text { negative pressures: } \\
\text { 50-200 kPa. }\end{array}$ & $\begin{array}{l}0.5 \mathrm{~mm} \text { needle hy- } \\
\text { drophone. (Precision } \\
\text { Acoustics, Dorset, } \\
\text { UK). } \\
\text { 3.5 MHz transducer. } \\
\text { (V380 Panametrics- } \\
\text { NDT, Waltham, MA, } \\
\text { USA). Focal length: } \\
75 \mathrm{~mm} \text {. Alignment: } \\
90^{\circ} .\end{array}$ & $\begin{array}{l}\text { SonoVue }{ }^{\circledR} \cdot(\text { Bracco } \\
\text { Research SA, } \\
\text { Geneva, Switzer- } \\
\text { land) }\end{array}$ & [29] \\
\hline $\begin{array}{l}\text { Attenuation } \\
\text { Scattering }\end{array}$ & $\begin{array}{l}1.5 \times 1.5 \times 4.5 \mathrm{~cm}^{3} \\
\text { sample vessel made } \\
\text { of acoustically trans- } \\
\text { parent polystyrene } \\
\text { membrane. }\end{array}$ & $\begin{array}{l}2.25 \mathrm{MHz} \text { transducer. } \\
\text { (A305S, Panametrics- } \\
\text { NDT, Waltham, MA, } \\
\text { USA). Focal length: } \\
25.4 \mathrm{~mm} \text {. }\end{array}$ & $\begin{array}{l}\text { Narrowband } \\
\text { 16-cycle pulses: } \\
0.7-5.5 \mathrm{MHz} \text {. Peak } \\
\text { negative pressure: } \\
10-100 \mathrm{kPa} . \\
\text { Narrowband } \\
\text { 16-cycle pulses: } \\
0.7-5.5 \mathrm{MHz} \text {. Peak } \\
\text { negative pressure: } \\
10-100 \mathrm{kPa} \text {. }\end{array}$ & $\begin{array}{l}5 \mathrm{MHz} \text { transducer. } \\
\text { (C308, Panametrics- } \\
\text { NDT, Waltham, MA, } \\
\text { USA). Focal length: } \\
25.4 \mathrm{~mm} \text {. } \\
3 \mathrm{MHz} \text { transducer. } \\
\text { (SR 885C1001, Ver- } \\
\text { mon, Tours, France). } \\
\text { Focal length: } 54.5 \\
\text { mm. Alignment: } 90^{\circ} \text {. }\end{array}$ & $\begin{array}{l}\text { Bracco BR-14. } \\
\text { (Bracco Research } \\
\text { SA, Geneva, Switzer- } \\
\text { land) }\end{array}$ & [7] \\
\hline Attenuation & $\begin{array}{l}100 \mathrm{~mL} \text { cylindrical } \\
\text { sample vessel with } \\
\text { internal diameter } \\
\text { of } 30 \mathrm{~mm} .12 .5 \mu \mathrm{m} \\
\text { acoustically transpar- } \\
\text { ent windows: } 20 \mathrm{~mm} \\
\text { diameter. }\end{array}$ & $\begin{array}{l}5 \mathrm{MHz} \text { transducer } \\
\text { (V310, Olympus In- } \\
\text { dustrial, Essex, UK). } \\
\text { Unfocused. }\end{array}$ & $\begin{array}{l}10 \mu \text { s pre-distorted } \\
\text { linear frequency- } \\
\text { modulated pulse: } \\
\text { 3-8 MHz. Peak } \\
\text { negative pressure: } \\
100 \mathrm{kPa} \text {. } \\
10 \mu \text { s tone burst: } \\
4 \mathrm{MHz} \text {. Peak neg- } \\
\text { ative pressures: } \\
50-300 \mathrm{kPa} \text {. }\end{array}$ & $\begin{array}{l}1 \mathrm{~mm} \text { needle hy- } \\
\text { drophone. (Precision } \\
\text { Acoustics, Dorset, } \\
\text { UK) } \\
1 \mathrm{~mm} \text { needle hy- } \\
\text { drophone. (Precision } \\
\text { Acoustics, Dorset, } \\
\text { UK). Alignment: } 90^{\circ} \text {. }\end{array}$ & $\begin{array}{l}\text { Liposome-loaded mi- } \\
\text { crobubbles produced } \\
\text { using microfluidic } \\
\text { manufacturing } \\
\text { process [32]. }\end{array}$ & [27] \\
\hline
\end{tabular}

The transmitter is typically excited with a short duration pulse [29] to excite the broadband response of the transducer or a linear frequency-modulated pulse [27] to obtain a broadband frequency response. By using a broadband transmission, the response of the microbubbles over a range of frequencies can be obtained in a short time. In other works, narrowband excitation is used [7,31]. Although some of this variation can be accounted for due to the different objectives of the research, it remains to be determined which approach is the most robust in characterising a microbubble population for direct comparison. 
The large amount of variation in the experimental setup and protocol used to characterise microbubbles makes it difficult to compare results across multiple research groups. This variability also makes it difficult to attribute any changes in measured characteristics to changes made to the microbubble population alone. An open access design for the acoustic characterisation of populations of microbubbles is presented. This design consists of 3D-printed parts that can be reproduced with ease. The Microbubble Acoustic Characterisation Chamber (MACC) aims to facilitate the characterisation of established and novel microbubbles. The designs are freely available to download (https://github.com/UARPGitHub/MACC) to enable a direct comparison across research groups. The latest information can be found in the corresponding knowledge base (https:/ / github.com/UARPGitHub/MACC/wiki). An experiment in which the scattering characteristics of SonoVue ${ }^{\circledR}$, a UCA with widely reported acoustic characteristics, was performed for the purposes of validating the presented design.

\section{Materials and Methods}

\subsection{Microbubble Acoustic Characterisation Chamber Design}

The Microbubble Acoustic Characterisation Chamber (MACC) was designed for acoustic measurements of populations of microbubbles. An image of the MACC, manufactured using an Objet1000 Multi-Material PolyJet 3D Printer (Stratasys, Minneapolis, MN, USA) in Vero ${ }^{\mathrm{TM}}$ material, is shown in Figure 1. The MACC consists of a central chamber that can accommodate up to six single-element transducer housings, an inlet housing, and outlet housing.

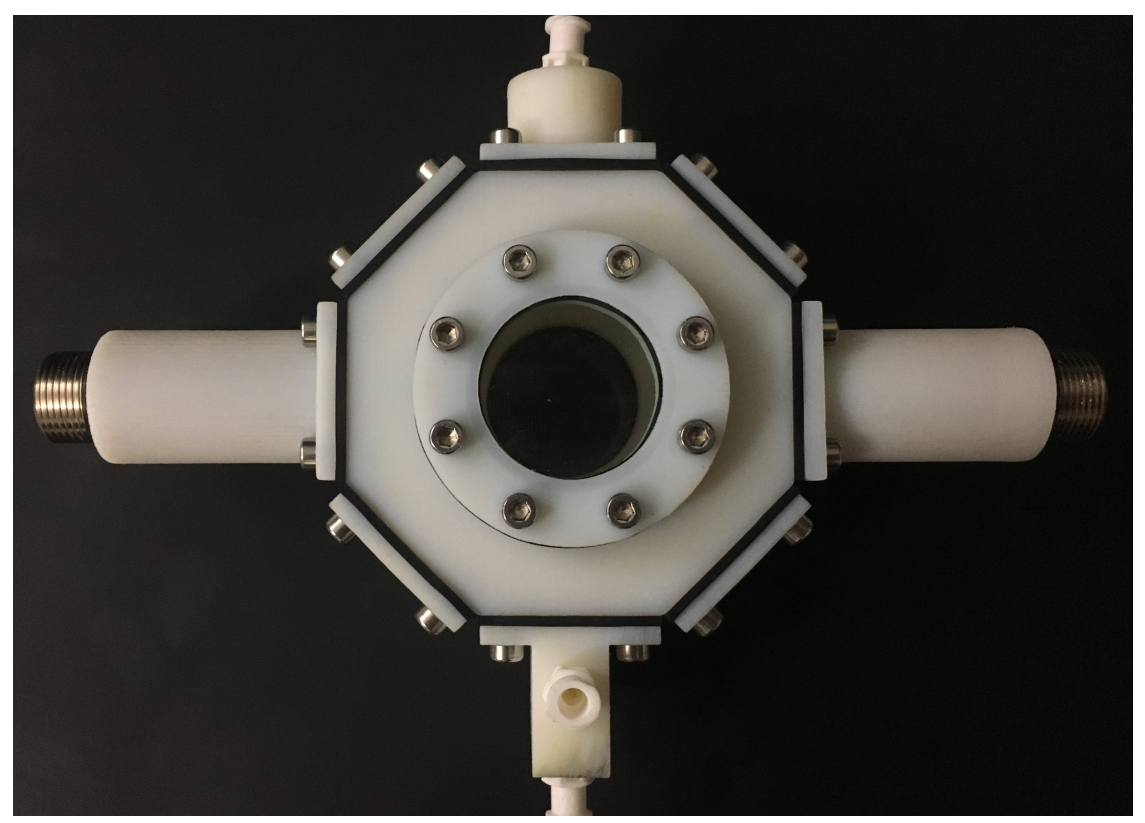

Figure 1. Microbubble Acoustic Characterisation Chamber populated with two $2.25 \mathrm{MHz}$ transducers (V323-SU, Olympus Industrial, Essex, UK), four blank inserts, the inlet housing, and the outlet housing.

The MACC chamber is an extruded octagon design, and 8 of the chamber's faces feature a $22 \mathrm{~mm}$-diameter channel. Transducer housings, the inlet housing and the outlet housing can be inserted into these channels. The other 2 faces feature $28 \mathrm{~mm}$-diameter channels to accommodate inspection window housings. The total dimensions of the central chamber are $70 \times 70 \times 28 \mathrm{~mm}$. The dimensions of the chamber represent a trade-off between limiting the internal volume, keeping the transducers operating in the far-field and reducing reverberations inside the chamber. Inspection windows allow a limited view inside the chamber and consist of $32 \mathrm{~mm}$-diameter, $3 \mathrm{~mm}$-thick, and clear acrylic disks situated in the inspection window housings. The central chamber features a series of $4 \mathrm{~mm}$ holes that are populated with M3threaded inserts. All housings are secured using M3 socket screws and $1.5 \mathrm{~mm}$-thick neoprene gaskets. The design files for the chamber, various housings, and neoprene gaskets are included 
in the repository. The list of parts and the assembly guide for the MACC can be found in the knowledge base (https: / / github.com/UARPGitHub/MACC/wiki/AssemblyGuide). The chamber was designed using Autodesk ${ }^{\circledR}$ Fusion 360. An exploded view of the MACC is shown in Figure 2.

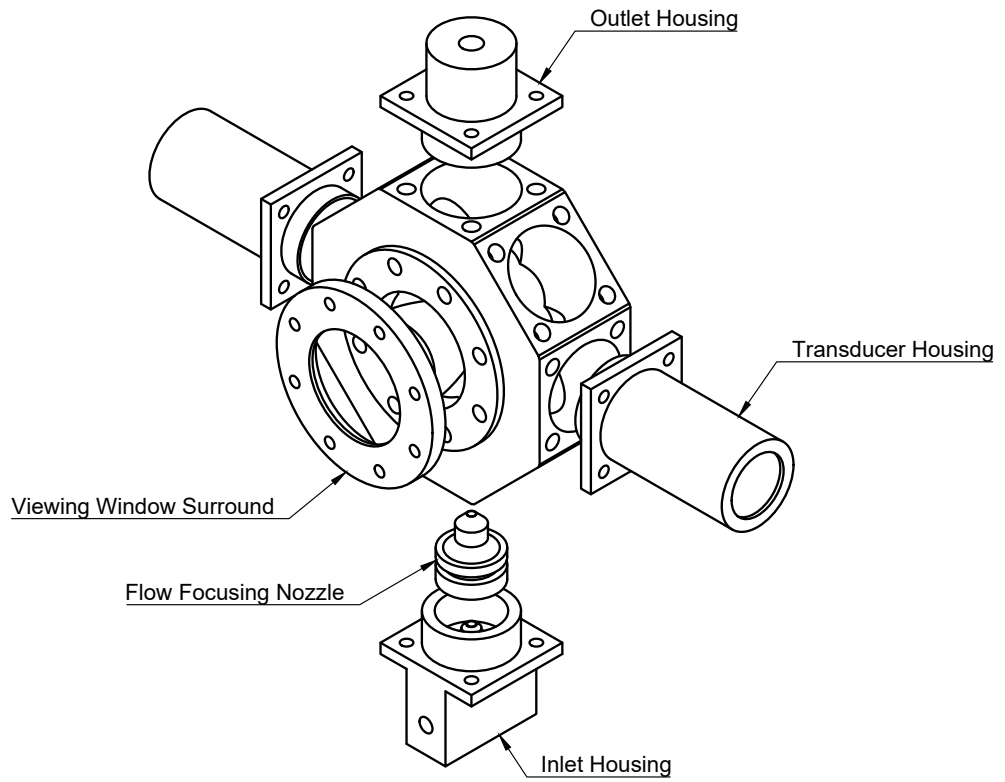

Figure 2. Exploded view of the Microbubble Acoustic Characterisation Chamber created using Autodesk ${ }^{\circledR}$ Fusion 360.

The MACC inlet housing consists of two coaxially aligned nozzles with $2 \mathrm{~mm}$ outlets. Careful control of a sheath flow and a sample flow at the two inlets in the inlet housing allow flow focusing of the microbubble sample. This constrains the microbubbles in the centre of the chamber and ensures they remain in the far-field of the transducers without the need for a barrier. The outlet housing is a funnel design with a waste outlet at the top of the chamber. Both of these housings have Luer lock adapters inserted for use with stopcocks and tubing. Syringe pumps are used to control the inlet flows and the outlet tube is positioned, so the waste sample is collected in a waste container placed below the chamber.

Transducer housings have been designed for Videoscan ${ }^{\circledR}$ transducers (V323-SU, V384SU, V310-SU, Olympus Industrial, Essex, UK). The transducer housings secure these transducers in a fixed position. A transducer is secured in the transducer housing by connecting a UHF plug to the UHF socket of the transducer. The chamber has been designed for use with pairs of unfocused $2.25 \mathrm{MHz}, 3.5 \mathrm{MHz}$, and $5 \mathrm{MHz}$ transducers. The pairs of transducers are placed inline with each other in the chamber for reference measurements. Backscatter is measured by the transmit transducer. All of the transducers are at a fixed distance of $35-37 \mathrm{~mm}$ from the centre of the chamber. Slight variations might be found due to the compressible neoprene gaskets. In addition to these housings, a design for a blank insert has also been provided that can be used to create acoustic absorbers or acoustic reflectors with the addition of an appropriate modification. These inserts can be used to create more flexible experimental setups. When less than the full complement of transducers are used with the chamber, these inserts can be used to make the chamber functional.

Figure 3 shows a schematic diagram of an experiment that can be used to measure the acoustic backscatter of a sample with a single pair of transducers and illustrates the concept behind the chamber design. This schematic corresponds to the chamber configuration illustrated in Figure 1. Transmitted waves propagate through a focused stream of the sample. The backscatter from this sample is received by the transmit transducer. A reference can be received using the inline transducer. By alternating the transmit transducer, both transducers can be used to obtain backscatter measurements. 


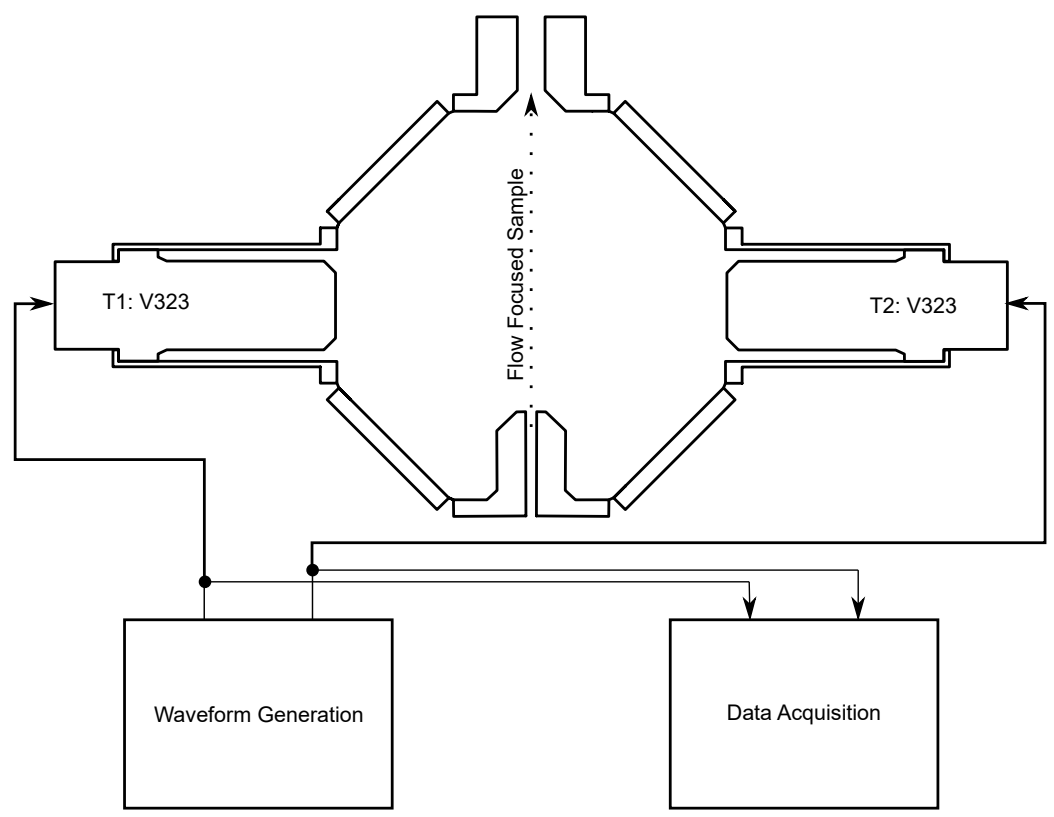

Figure 3. Schematic of acoustic experiment to measure the backscatter using a single pair of 2.25 $\mathrm{MHz}$ transducers.

Figure 4 shows the internal structure of a chamber configuration in which all six transducers are used. The transducers are aligned towards the centre of the chamber, allowing the reference to be measured on one transducer and scattering to be measured on up to five transducers from a single transmit event. By incorporating transducers with central frequencies over the range of 2.25 to $5 \mathrm{MHz}$, a broad range of frequencies around the typical resonant frequency of microbubbles can be investigated without the need for a needle hydrophone. Figure 4 highlights the internal structure of the inlet housing in which two coaxially aligned nozzles achieve flow focusing.

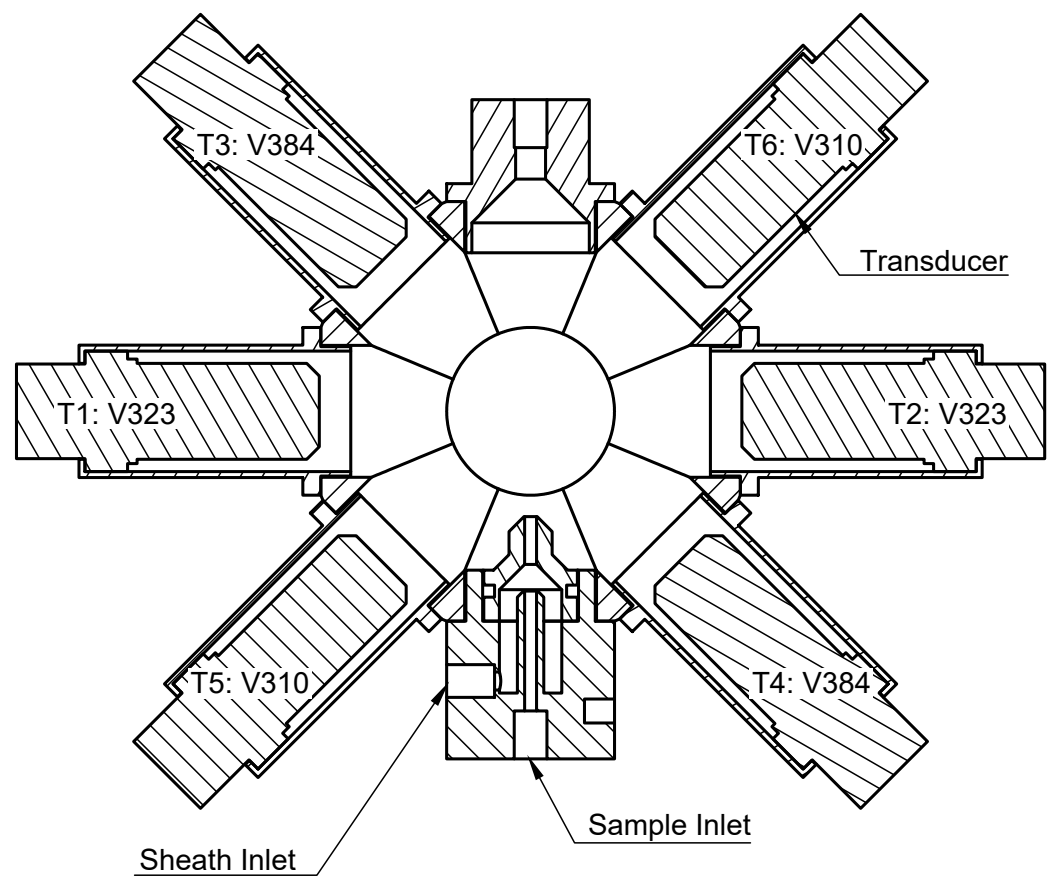

Figure 4. Cross-section of the Microbubble Acoustic Characterisation Chamber showing the internal structure and the position of the transducers during the experiment. Created using Autodesk ${ }^{\circledR}$ Fusion 360. 


\subsection{Experiment Design}

The MACC design has been used to measure the acoustic scattering at the fundamental frequency and second harmonic of SonoVue ${ }^{\circledR}$ microbubbles. The experiment was performed with a 16-channel variant of the Ultrasound Array Research Platform (UARPII16) developed at the University of Leeds and shown in Figure 5. This open platform allows the connection of 16 single-element transducers and can transmit and receive on all 16 channels simultaneously. The MACC, UARPII-16, and all six unfocused transducers were used to perform an experiment to assess the suitability of the entire setup for microbubble acoustic measurements [33]. Whilst the UARPII-16 was used in this instance, it could have been replaced with another multi-channel system providing access to the radio-frequency data from every channel [34] such as the NDT Vantage ${ }^{\mathrm{TM}}$ (Verasonics ${ }^{\circledR}$, Kirkland, WA, USA) research solutions. Alternatively, a setup consisting of an arbitrary waveform generator, power amplifier, and oscilloscope $[7,27,29]$ could be used, provided this setup accommodates six channels.

The UARPII-16 uses a quinary switched excitation method [35] to excite the transducers. This method allows the synthesis of an arbitrary waveform. Narrowband pulses, with a $10 \mu$ s duration, were used as excitation waveforms. The waveforms were stepped in frequency ranging from 1.6 to $6.4 \mathrm{MHz}$ at increments of $0.2 \mathrm{MHz}$. Only the waveforms that fell within the $60 \%$ fractional bandwidth of a transducer were used with that transducer. This ensured that the frequency measurements from the various transducers overlapped whilst operating within reasonable limits of the transducer bandwidth. The waveforms were windowed using a Tukey window with a 0.2 Cosine fraction. The transducer response to these waveforms was measured before the experiment using a membrane hydrophone (Precision Acoustics, Dorset, UK) in a large water tank filled with deionised water. The membrane hydrophone was positioned to record the maximum pressure at a distance of $35 \mathrm{~mm}$ from the transducer under test. An oscilloscope (MSO-S 204 A, Keysight Technologies, Berkshire, UK) was used to obtain 128 acquisitions, and these were subsequently averaged in the time-domain. The resulting waveforms were windowed to obtain the central $5 \mu$ s of the received pulse and inverse filtered using the hydrophone frequency response to obtain the pressure value corresponding to the maximum amplitude in the frequency domain. The amplitude of the transmit waveform was then pre-distorted to obtain a uniform $70 \mathrm{kPa}$ root mean square (RMS) pressure at the transmit frequency used for each transducer. This was validated through further measurements with the membrane hydrophone.

The chamber was populated with all six transducers, and the pairs of transducers corresponding to the same central frequency were placed in line with each other according to Figure 4 . The chamber was filled with deionised water. Due to the geometry of the chamber, it is possible for air to accumulate and become trapped within the upper two transducer housings. To prevent this from happening, the outlet stopcock was closed, and the upper transducer connectors were loosened during the initial filling stage to allow air to escape through the top of the upper transducer housings. The connectors were then tightened once more, and the outlet stopcock was opened for experimental measurements. A total of $110 \mathrm{~mL}$ of water was required to fill the chamber. Flow rates were assessed before the experiment when characterising the chamber. During this assessment, dye was applied to the sample to visualise the flow-focusing behaviour. A sheath flow rate of $22 \mathrm{~mL}$ per minute and a sample flow rate of $7 \mathrm{~mL}$ per minute were determined to provide a stable sample stream. This resulted in the sample being constrained to a stream approximately $1 \mathrm{~mm}$ in diameter in the centre of the chamber. It is worth noting that this process should be repeated for individually manufactured inlet housings to account for manufacturing discrepancies.

The pulse repetition frequency for the experiment was set to $500 \mathrm{~Hz}$, and each of the frequencies assigned to a given transducer were repeated 64 times for the transducer. The individual insonifications were distributed throughout the experiment duration. The experiment was repeated 12 times with a fresh 1:1000 dilution of SonoVue ${ }^{\circledR}($ Bracco, Milan, 
Italy), 12 times with a fresh 1:2500 dilution of SonoVue ${ }^{\circledR}$ and 12 times with deionised water to provide a reference. The dilutions were prepared from a single vial of SonoVue immediately before use. The choice between which sample was measured first was alternated for each repeat, and the reference measurement was taken last.

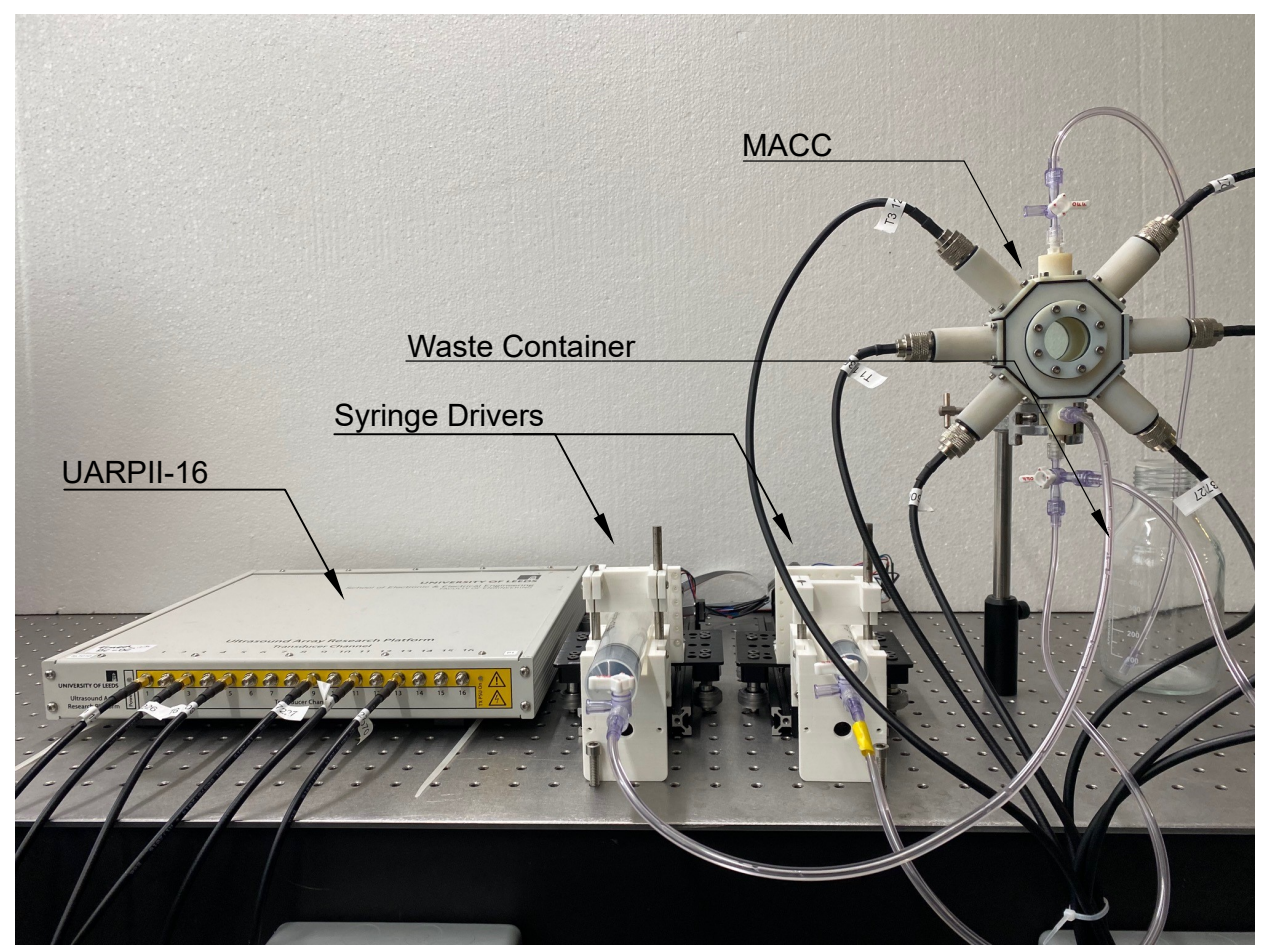

Figure 5. This experimental setup was used to measure the acoustic scattering of SonoVue ${ }^{\circledR}$ microbubbles over the frequency range 1.6 to $6.4 \mathrm{MHz}$.

\subsection{Signal Processing}

Signal processing was performed in MATLAB ${ }^{\circledR}$. For each of the 64 repetitions corresponding to a particular acoustic measurement, the received data were windowed using a square window to obtain an integer number of cycles and a temporal length of approximately $5 \mu \mathrm{s}$. The start of the window was selected to coincide with the start of a cycle and was delayed by approximately $51 \mu$ s from the start of the transmit event. These values were chosen to avoid any transients at the start or end of the pulse. The windowed signals were filtered between $100 \mathrm{kHz}$ and $10 \mathrm{MHz}$ using a fourth-order Butterworth bandpass filter. An average RMS amplitude spectrum was obtained from the windowed data of the 64 repetitions. In order to convert the amplitude spectrum to a pressure spectrum, a frequency-dependent receiver sensitivity was calculated for each transducer. This sensitivity was calculated from the calibration pressure measurements obtained with the membrane hydrophone for each transmit waveform. The average RMS amplitudes of the reference measurements, at the fundamental frequency and obtained using the inline transducer with only deionised water in the chamber, were assumed to correspond to the calibration pressure at the same frequency. Scattering measurements in decibels were determined using the pressure spectrum according to the following equation:

$$
S\left(f_{s}\right)=20 \log \frac{\left|P_{\text {scat }}\left(f_{S}\right)\right|}{\left|P_{\text {ref }}\right|}
$$

where $P_{\text {scat }}$ is the RMS pressure spectrum corresponding to the recorded scattering signal at the frequency of interest $f_{s}$, and $P_{r e f}$ is the RMS pressure component at the fundamental frequency of the calibration measurements. Because the amplitude spectrum is recorded using a different receiver to the reference, the conversion to pressure was required to make the recorded data independent of the receiving transducer's frequency-dependent sensitivity. 


\section{Results}

For every acoustic scattering measurement presented in this section, a two-tailed t-test was performed between the average RMS amplitude component of the received data corresponding to a scattering measurement and a reference measurement in which no microbubbles were present. The null hypothesis that "the introduction of microbubbles into the acoustic path has no effect on the amplitude component at frequency $f_{s}$ " was rejected at the $5 \%$ significance level for all of the amplitude components used to determine the scattering characteristics in the remainder of this section. This gives confidence that the MACC is suitable for performing microbubble scattering measurements.

Figure 6 shows the fundamental backscatter calculated over the frequency range of 1.6-6.4 MHz using Equation (1). The mean backscatter values from Figure 6a are included in Appendix Table A1 and for Figure 6b in Appendix Table A2. From Figure 6, it can be seen that the scattering from SonoVue ${ }^{\circledR}$ is highest at the lowest frequencies investigated. This is in general agreement with previous studies [31]. As is expected, because the measured scattering is the summation of the scattering from individual microbubbles, the lower dilution sample resulted in a lower scattering value. Both dilutions show the same general trend with frequency, and this gives confidence that the chamber is suitable for the measurement of dilutions of SonoVue ${ }^{\circledR}$ in the range of clinical doses. The measurements from the various transducers also overlap and are in general agreement with regards to the overall trend. For the pairs of transducers that are used to investigate the same frequency range, the scattering measurements are in agreement. This is further validation that the measurements are reliable. There is some discrepancy between the scattering values at the frequencies that overlap between different transducer pairs. This is likely due to mismatches in the transducer sensitivity compounded by the limits of the usable bandwidth for a transducer. This highlights the importance of performing the experiment within reasonable frequency limits for a given transducer and in the robust calibration of transducer receive-sensitivity.

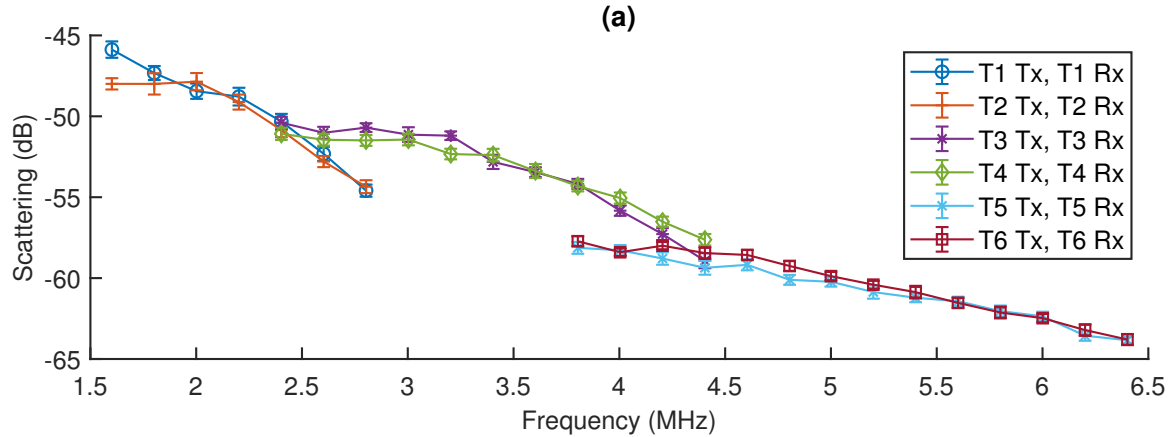

(b)

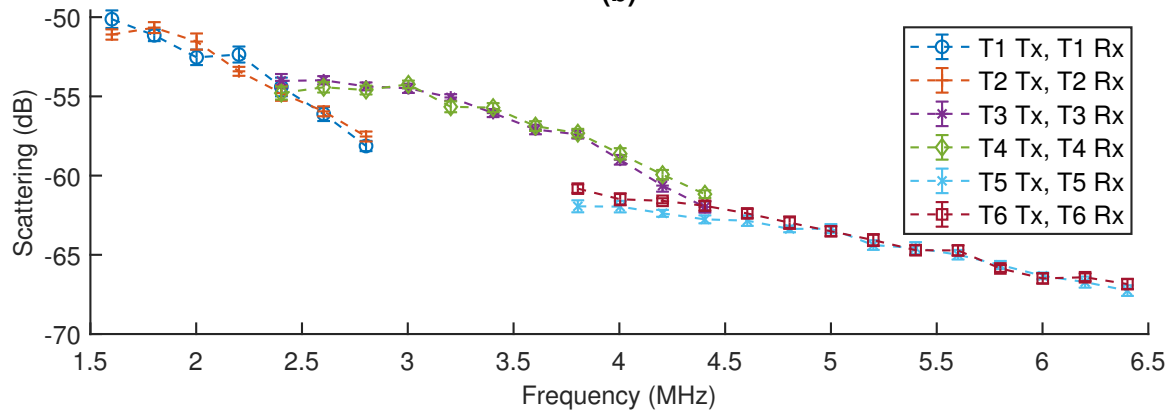

Figure 6. Measured backscatter at the fundamental frequency over the frequency range of 1.6-6.4 MHz for (a) the 1:1000 and (b) the 1:2500 dilutions of SonoVue ${ }^{\circledR}$. Measurement scattering signals were recorded using the transmit transducer as a receiver. The error bars reflect the standard error over the 12 experiment repetitions. 
Figure 7 shows the average RMS pressure spectrum obtained using various transducers from the first acquisition and for a transmit frequency of $1.6 \mathrm{MHz}$ transmitted using a $2.25 \mathrm{MHz}$ transducer (T1 in Figure 4). The spectrum measured using the inline 2.25 MHz transducer (T2 in Figure 4) for the reference measurement is included in Figure 7a. Figure $7 \mathrm{~b}$ shows the backscattered data received by the transmit transducer ( $\mathrm{T} 1$ in Figure 4) at the fundamental frequency and second harmonic. The second harmonic response is very low. This can be accounted for due to the limited bandwidth of the transducer. Figure $7 \mathrm{c}$ shows the data received by a $3.5 \mathrm{MHz}$ transducer (T3 in Figure 4). In this case, the fundamental response is low, but the second harmonic is more pronounced. Figure $7 \mathrm{~d}$ shows the combination of the fundamental response recorded by the transmit transducer and the second harmonic recorded by the $3.5 \mathrm{MHz}$ transducer. It highlights how the signal received on multiple transducers can be combined to obtain the frequency response over a broader range of frequencies than would be possible with just a single receive transducer. It should be noted that the fusion of data from different receivers relies on the ability to obtain an accurate RMS pressure value for the receiver amplitude.

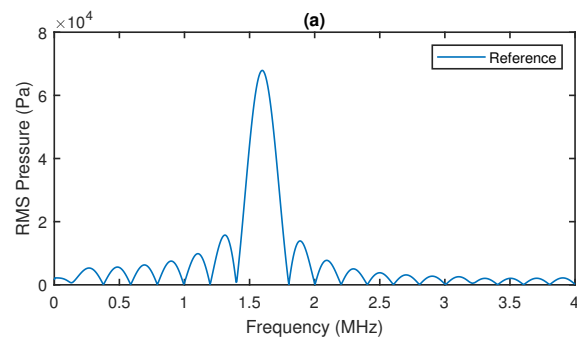

(c)

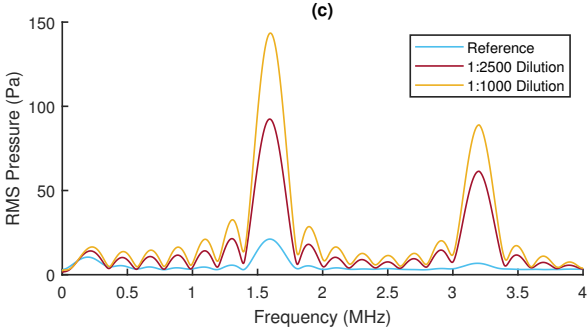

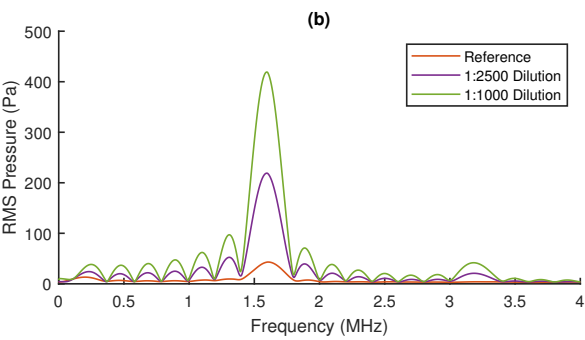

(d)

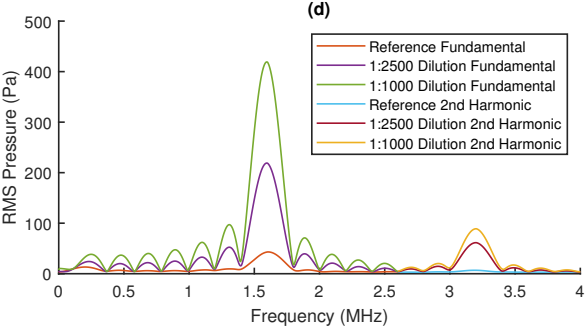

Figure 7. Root mean square (RMS) pressure spectra for $1.6 \mathrm{MHz}$ insonification using $\mathrm{T} 1$ and received on (a) T2, (b) T1, and (c) T3 as illustrated in Figure 4. (d) Combined RMS pressure spectrum with T1 used to measure scattering at the fundamental frequency and T3 used to measure scattering at the second harmonic.

Figure 8 shows the second harmonic scattering calculated over the frequency range of 3.2-6.4 MHz using various receive transducers and Equation (1). The mean backscatter values from Figure 8a are included in Appendix Table A3 and for Figure 8b in Appendix Table A4. The scattering at the second harmonic shows the same trend as the scattering at the fundamental frequencies. The insonifications that provided the maximum scattering response at the fundamental frequency also provide the maximum at the second harmonic. Once again, the measurements from the various transducers overlap, and the lower dilution measurement resulted in lower scattering values. 
(a)

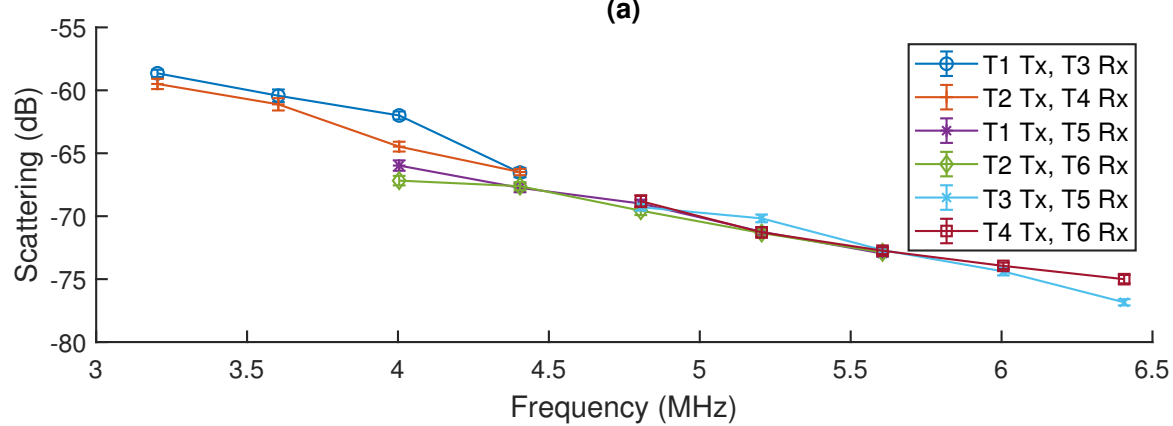

(b)

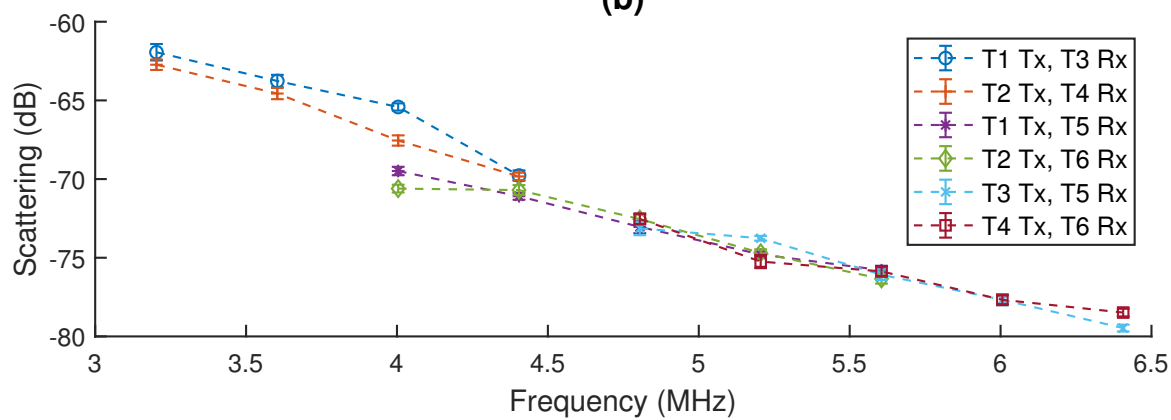

Figure 8. Measured scattering at the second harmonic over the frequency range of 3.2-6.4 MHz for (a) the 1:1000 and (b) the 1:2500 dilutions of SonoVue ${ }^{\circledR}$. The error bars reflect the standard error over the 12 experiment repetitions.

\section{Discussion}

A statistically significant difference was found for all the reported acoustic measurements between the measured control sample, containing only deionised water, and the measured sample for both dilutions of contrast agent. Furthermore, the scattering characteristics measured are in agreement with previous studies [31] for the ultrasound contrast agent SonoVue ${ }^{\circledR}$. By performing the measurements in both directions across the chamber, a great degree of confidence can be taken in the measured characteristics. For all the measurements taken, the lower dilution sample resulted in a lower scattering value. This validates the efficacy of the MACC for performing scattering measurements at both the fundamental frequency and the second harmonic.

The motivation behind the MACC is to provide a standardised piece of equipment for characterising microbubbles acoustically. In this work, narrowband waveforms were used to interrogate the sample at fixed frequency intervals. An alternative approach might have been to use broadband waveforms to obtain the response over a range of frequencies. The transmission parameters and digital signal processing steps required to obtain a robust acoustic characterisation methodology that can be used for differing research objectives and across research groups are yet to be determined. In this work, it was necessary to pre-distort the transmitted waveforms to obtain uniform pressures across a range of frequencies and transducers. It was also necessary to account for the sensitivity of the different transducers at different frequencies in receive. Without these steps, it would not have been possible to fuse the data from different transducers.

In providing a unified piece of equipment, it is possible for researchers in different locations to reproduce results. Researchers are able to share the parameters of the interrogating acoustic waves and flow rates used with the chamber alongside results. It is envisaged that, with a more standardised apparatus, a consistent protocol can be developed and direct comparison across research groups will become possible.

Due to the vast range of research objectives that may be encountered when characterising microbubbles, it is difficult to create a single piece of equipment to cover all possible scenarios. The MACC has been designed to allow a flexible configuration. The chamber, in 
its current form, allows the incorporation of absorbers and reflectors. These can be used at the expense of removing one or more of the transducers. Whilst the transducers chosen in this study offer the ability to investigate a broad range of frequencies around those typically required for microbubble characterisation, they are interchangeable, and transducers covering different frequency ranges may be used. For instance, if research objectives require the measurement of a lower fundamental frequency or sub-harmonic measurements, a pair of transducers with a central frequency of $1 \mathrm{MHz}$ could be incorporated. Other research objectives may require attenuation measurements. Typically, attenuation measurements are made through a microbubble screen that is wider than the beam width. At the expense of performing the measurements in both directions across the chamber, the unfocused transducers on one side of the chamber could be replaced with focused transducers. By ensuring these focused transducers have a fixed focal depth coinciding with the sample stream, they could be used for the sole purpose of measuring attenuation.

The MACC has been released to allow other researchers the ability and freedom to modify and extend the design. Future modifications might include the incorporation of optics to provide optical characterisation capabilities. Another possible modification is the incorporation of an acoustic window housing to allow a phased array cardiac probe to be used to image the flowing microbubbles. Further modification and extensions to the MACC are welcomed.

\section{Conclusions}

In this work, a chamber for the characterisation of microbubbles was developed. The chamber was assessed with an experiment to measure the scattering characteristics of SonoVue ${ }^{\circledR}$. For all acoustic measurements used in the determination of the scattering characteristics, t-tests were performed to ensure the measured data were statistically significant when compared to the control data. Scattering at the fundamental frequency and at the second harmonic were determined. The measurements were found to be in agreement with previously published measurements. These findings give confidence that the design is suitable for performing acoustic scattering measurements of UCAs. By releasing the MACC as open access, the chamber is well placed for wider adoption by the research community. This will facilitate direct comparison across research groups and will allow other researchers to contribute to the evolution of the design.

Supplementary Materials: The following are available online at https:/ / www.mdpi.com/article/10 .3390/app12041818/s1, S1: Scattering Data, S2: T1 Transmit Average RMS Amplitude Spectrums, S3: T2 Transmit Average RMS Amplitude Spectrums, S4: T3 Transmit Average RMS Amplitude Spectrums, S5: T4 Transmit Average RMS Amplitude Spectrums, S6: T5 Transmit Average RMS Amplitude Spectrums, S7: T6 Transmit Average RMS Amplitude Spectrums. The follow is available online at https:/ / github.com/UARPGitHub/MACCProcessing, S8: MATLAB ${ }^{\circledR}$ Processing Code For Supplementary Files S2-S7. The follow is available online at https:/ /github.com/UARPGitHub / MACC, S9: Microbubble Acoustic Characterisation Design Files. The follow is available online at https://github.com/UARPGitHub/MACC/wiki, S10: Microbubble Acoustic Characterisation Knowledge Base And Assembly Guide.

Author Contributions: Conceptualization, E.S., J.M., D.C. and S.F.; methodology, E.S., L.N., J.M. and S.F.; software, E.S., H.C. and T.C.; validation, E.S.; formal analysis, E.S.; investigation, E.S.; resources, J.M., D.C. and S.F.; data curation, E.S.; writing—original draft preparation, E.S.; writing-review and editing, E.S., L.N., J.M., H.C., T.C., D.C., S.E., A.F.F. and S.F.; visualization, E.S.; supervision, S.F., A.F.F. and S.E.; project administration, S.F.; funding acquisition, S.F. and S.E. All authors have read and agreed to the published version of the manuscript.

Funding: This research was funded by EPSRC grants number EP/P023266/1 and EP/V04799X/1. A.F.F. is partially funded by a RAEng Chair in Emerging Technologies (CiET1819/19)

Institutional Review Board Statement: Not applicable.

Informed Consent Statement: Not applicable. 
Data Availability Statement: The data presented in this study are available in Supplementary Material S1-S7.

Acknowledgments: The author would like to thank the Microbubble Consortium at the University of Leeds.

Conflicts of Interest: The authors declare no conflict of interest.

\section{Abbreviations}

The following abbreviations are used in this manuscript:

$\begin{array}{ll}\text { UCAs } & \text { Ultrasound Contrast Agents } \\ \text { LVO } & \text { Left Ventricular Opacification } \\ \text { MI } & \text { Mechanical Index } \\ \text { MACC } & \text { Microbubble Acoustic Characterisation Chamber } \\ \text { RMS } & \text { Root Mean Square } \\ \text { FDA } & \text { Food and Drug Administration } \\ \text { NDT } & \text { Non-Destructive Test } \\ \text { UHF } & \text { Ultra-High Frequency }\end{array}$

\section{Appendix A}

Table A1. Mean backscatter at the fundamental frequency over the frequency range $1.6-6.4 \mathrm{MHz}$ for the 1:1000 dilutions of SonoVue ${ }^{\circledR}$. The transmitter receiver configuration is denoted transmitter/receiver.

\begin{tabular}{|c|c|c|c|c|c|c|}
\hline \multirow[t]{2}{*}{$\begin{array}{l}\text { Frequency } \\
\text { (MHz) }\end{array}$} & \multicolumn{6}{|c|}{$\begin{array}{l}\text { Scattering } \\
\text { (dB) }\end{array}$} \\
\hline & T1/T1 & $\mathrm{T} 2 / \mathrm{T} 2$ & T3/T3 & $\mathrm{T} 4 / \mathrm{T} 4$ & T5/T5 & T6/T6 \\
\hline 1.6 & -45.9 & -48.0 & - & - & - & - \\
\hline 1.8 & -47.3 & -48.0 & - & - & - & - \\
\hline 2.0 & -48.4 & -47.9 & - & - & - & - \\
\hline 2.2 & -48.8 & -49.1 & - & - & - & - \\
\hline 2.4 & -50.3 & -50.9 & -50.4 & -51.1 & - & - \\
\hline 2.6 & -52.3 & -52.8 & -51.0 & -51.4 & - & - \\
\hline 2.8 & -54.6 & -54.4 & -50.7 & -51.5 & - & - \\
\hline 3.0 & - & - & -51.1 & -51.4 & - & - \\
\hline 3.2 & - & - & -51.2 & -52.3 & - & - \\
\hline 3.4 & - & - & -52.8 & -52.4 & - & - \\
\hline 3.6 & - & - & -53.5 & -53.4 & - & - \\
\hline 3.8 & - & - & -54.2 & -54.3 & -58.1 & -57.7 \\
\hline 4.0 & - & - & -55.8 & -55.1 & -58.3 & -58.4 \\
\hline 4.2 & - & - & -57.3 & -56.5 & -58.8 & -58.0 \\
\hline 4.4 & - & - & -58.9 & -57.6 & -59.4 & -58.5 \\
\hline 4.6 & - & - & - & - & -59.2 & -58.6 \\
\hline 4.8 & - & - & - & - & -60.1 & -59.3 \\
\hline 5.0 & - & - & - & - & -60.2 & -59.9 \\
\hline 5.2 & - & - & - & - & -60.9 & -60.4 \\
\hline 5.4 & - & - & - & - & -61.2 & -60.9 \\
\hline 5.6 & - & - & - & - & -61.4 & -61.5 \\
\hline 5.8 & - & - & - & - & -62.0 & -62.1 \\
\hline 6.0 & - & - & - & - & -62.4 & -62.5 \\
\hline 6.2 & - & - & - & - & -63.6 & -63.2 \\
\hline 6.4 & - & - & - & - & -63.8 & -63.8 \\
\hline
\end{tabular}

Table A2. Mean backscatter at the fundamental frequency over the frequency range $1.6-6.4 \mathrm{MHz}$ for the 1:2500 dilutions of SonoVue ${ }^{\circledR}$. The transmitter receiver configuration is denoted transmitter/receiver.

\begin{tabular}{|c|c|c|c|c|c|c|}
\hline \multirow[t]{2}{*}{$\begin{array}{c}\text { Frequency } \\
\text { (MHz) }\end{array}$} & \multicolumn{6}{|c|}{$\begin{array}{c}\text { Scattering } \\
(\mathrm{dB})\end{array}$} \\
\hline & $\mathrm{T} 1 / \mathrm{T} 1$ & $\mathrm{~T} 2 / \mathrm{T} 2$ & T3/T3 & $\mathrm{T} 4 / \mathrm{T} 4$ & T5/T5 & T6/T6 \\
\hline $\begin{array}{l}1.6 \\
1.8 \\
2.0 \\
2.2 \\
2.4 \\
2.6 \\
2.8\end{array}$ & $\begin{array}{l}-50.1 \\
-51.1 \\
-52.5 \\
-52.4 \\
-54.4 \\
-56.1 \\
-58.1\end{array}$ & $\begin{array}{l}-51.1 \\
-50.7 \\
-51.5 \\
-53.4 \\
-54.8 \\
-55.9 \\
-57.5\end{array}$ & $\begin{array}{c}- \\
- \\
- \\
- \\
-54.0 \\
-54.0 \\
-54.4\end{array}$ & $\begin{array}{c}- \\
- \\
- \\
- \\
-54.8 \\
-54.4 \\
-54.6\end{array}$ & $\begin{array}{l}- \\
- \\
- \\
- \\
- \\
- \\
-\end{array}$ & $\begin{array}{l}- \\
- \\
- \\
- \\
- \\
- \\
-\end{array}$ \\
\hline
\end{tabular}


Table A2. Cont.

\begin{tabular}{|c|c|c|c|c|c|c|}
\hline \multirow{2}{*}{$\begin{array}{c}\text { Frequency } \\
\text { (MHz) }\end{array}$} & \multicolumn{6}{|c|}{$\begin{array}{l}\text { Scattering } \\
\text { (dB) }\end{array}$} \\
\hline & - & - & -54.5 & -54.2 & - & - \\
\hline 3.2 & - & - & -55.1 & -55.7 & - & - \\
\hline 3.4 & - & - & -56.1 & -55.7 & - & - \\
\hline 3.6 & - & - & -57.1 & -56.9 & - & - \\
\hline 3.8 & - & - & -57.4 & -57.3 & -61.9 & -60.8 \\
\hline 4.0 & - & - & -59.0 & -58.6 & -62.0 & -61.5 \\
\hline 4.2 & - & - & -60.6 & -59.9 & -62.4 & -61.6 \\
\hline 4.4 & - & - & -62.0 & -61.2 & -62.8 & -61.9 \\
\hline 4.6 & - & - & - & - & -62.8 & -62.4 \\
\hline 4.8 & - & - & - & - & -63.4 & -63.0 \\
\hline 5.0 & - & - & - & - & -63.3 & -63.5 \\
\hline 5.2 & - & - & - & - & -64.4 & -64.1 \\
\hline 5.4 & - & - & - & - & -64.6 & -64.7 \\
\hline 5.6 & - & - & - & - & -65.0 & -64.7 \\
\hline 5.8 & - & - & - & - & -65.6 & -65.9 \\
\hline 6.0 & - & - & - & - & -66.3 & -66.5 \\
\hline 6.2 & - & - & - & - & -66.7 & -66.4 \\
\hline 6.4 & - & - & - & - & -67.3 & -66.8 \\
\hline
\end{tabular}

Table A3. Mean scattering at the second harmonic over the frequency range 3.2-6.4 MHz for the 1:1000 dilutions of SonoVue ${ }^{\circledR}$. The transmitter receiver configuration is denoted transmitter/receiver.

\begin{tabular}{ccccccc}
\hline $\begin{array}{c}\text { Frequency } \\
\text { (MHz) }\end{array}$ & \multicolumn{7}{c}{$\begin{array}{c}\text { Scattering } \\
(\mathbf{d B})\end{array}$} \\
\hline & $\mathrm{T} 1 / \mathrm{T} 3$ & $\mathrm{~T} 1 / \mathrm{T} 5$ & $\mathrm{~T} 2 / \mathrm{T} 4$ & $\mathrm{~T} 2 / \mathrm{T} 6$ & $\mathrm{~T} 3 / \mathrm{T} 5$ & $\mathrm{~T} 4 / \mathrm{T} 6$ \\
\cline { 2 - 6 } 3.2 & -58.6 & - & -59.5 & - & - & - \\
3.6 & -60.4 & - & -61.1 & - & - & - \\
4.0 & -62.0 & -66.0 & -64.5 & -67.2 & - & - \\
4.4 & -66.5 & -67.7 & -66.5 & -67.6 & - & - \\
4.8 & - & -69.0 & - & -69.6 & -69.3 & -68.8 \\
5.2 & - & -71.2 & - & -71.3 & -70.2 & -71.3 \\
5.6 & - & -73.0 & - & -72.9 & -72.7 & -72.7 \\
6.0 & - & - & - & - & -74.4 & -73.9 \\
6.4 & - & - & - & - & -76.8 & -75.0 \\
\hline
\end{tabular}

Table A4. Mean scattering at the second harmonic over the frequency range 3.2-6.4 MHz for the 1:2500 dilutions of SonoVue ${ }^{\circledR}$. The transmitter receiver configuration is denoted transmitter/receiver.

\begin{tabular}{ccccccc}
\hline $\begin{array}{c}\text { Frequency } \\
\text { (MHz) }\end{array}$ & \multicolumn{7}{c}{$\begin{array}{c}\text { Scattering } \\
\text { (dB) }\end{array}$} \\
\hline & $\mathrm{T} 1 / \mathrm{T} 3$ & $\mathrm{~T} 1 / \mathrm{T} 5$ & $\mathrm{~T} 2 / \mathrm{T} 4$ & $\mathrm{~T} 2 / \mathrm{T} 6$ & $\mathrm{~T} 3 / \mathrm{T} 5$ & $\mathrm{~T} 4 / \mathrm{T} 6$ \\
\cline { 2 - 7 } 3.2 & -61.9 & - & -62.7 & - & - & - \\
3.6 & -63.8 & - & -64.6 & - & - & - \\
4.0 & -65.4 & -69.5 & -67.5 & -70.6 & - & - \\
4.4 & -69.8 & -71.1 & -69.8 & -70.7 & - & -72.5 \\
4.8 & - & -73.0 & - & -72.5 & -73.1 & -75.2 \\
5.2 & - & -74.8 & - & -74.7 & -73.8 & -75.9 \\
5.6 & - & -75.8 & - & -76.3 & -76.1 & -77.7 \\
6.0 & - & - & - & - & -77.7 & -78.5 \\
6.4 & - & - & - & - & & -5 \\
\hline
\end{tabular}

\section{References}

1. Hoff, L. Acoustic Characterization of Contrast Agents for Medical Ultrasound Imaging, 1st ed.; Kluwer Academic Publishers: Dordrecht, The Netherlands, 2001; pp. 7-41.

2. Medwin, H. Counting bubbles acoustically: A review. Ultrasonics 1977, 15, 7-13. [CrossRef]

3. De Jong, N.; Emmer, M.; van Wamel, A.; Versluis, M. Ultrasonic characterization of ultrasound contrast agents. Med. Biol. Eng. Comput. 2009, 47, 861-873. [CrossRef] [PubMed]

4. De Jong, N.; Hoff, L.; Skotland, T.; Bom, N. Absorption and scatter of encapsulated gas filled microspheres: Theoretical considerations and some measurements. Ultrasonics 1992, 30, 95-103. [CrossRef]

5. Church, C. The effects of an elastic solid surface layer on the radial pulsations of gas bubbles. J. Acoust. Soc. Am. 1995, 97, 1510-1521. [CrossRef]

6. Prosperetti, A. Acoustic cavitation series: Part two; Bubble phenomena in sound fields: Part one. Ultrasonics $1984,22,69-77$. [CrossRef]

7. Segers, T.; de Jong, N.; Versluis, M. Uniform scattering and attenuation of acoustically sorted ultrasound contrast agents: Modeling and experiments. J. Acoust. Soc. Am. 2016, 140, 2506-2517. [CrossRef] [PubMed] 
8. Senior, R.; Becher, H.; Monaghan, M.; Agati, L.; Zamorano, J.; Vanoverschelde, J.; Nihoyannopoulos, P.; Edvardsen, T.; Lancellotti, P. Clinical practice of contrast echocardiography: Recommendation by the European Association of Cardiovascular Imaging (EACVI) 2017. Eur. Heart J. Cardiovasc. Imaging 2017, 18, 1205. [CrossRef]

9. Stride, E.; Saffari, N. Microbubble ultrasound contrast agents: A review. Proc. Inst. Mech. Eng. H 2003, 217, 429-447. [CrossRef]

10. Chomas, J.; Dayton, P.; Allen, J.; Morgan, K.; Ferrara, K. Mechanisms of contrast agent destruction. IEEE Trans. Ultrason Ferroelectr. Freq. Contr. 2001, 48, 232-248. [CrossRef]

11. Versluis, M.; Stride, E.; Lajoinie, G.; Dollet, B.; Segers, T. Ultrasound contrast agent modeling: A review. Ultrasound Med Biol 2020, 46, 2117-2144. [CrossRef]

12. Schrope, B.; Newhouse, V. Second harmonic ultrasonic blood perfusion measurement. Ultrasound Med. Biol. 1993, 19, 567-579. [CrossRef]

13. Forsberg, F.; Shi, W.; Goldberg, B. Subharmonic imaging of contrast agents. Ultrasonics 2000, 38, 93-98. [CrossRef]

14. Simpson, D.; Chin, C.; Burns, P. Pulse inversion Doppler: A new method for detecting nonlinear echoes from microbubble contrast agents. IEEE Trans. Ultrason Ferroelectr. Freq. Contr. 1999, 46, 372-382. [CrossRef]

15. Eckersley, R.; Chin, C.; Burns, P. Optimising phase and amplitude modulation schemes for imaging microbubble contrast agents at low acoustic power. Ultrasound Med. Biol. 2005, 31, 213-219. [CrossRef]

16. Food and Drug Administration. Marketing Clearance of Diagnostic Ultrasound Systems and Transducers. 2019. Available online: https:/ / www.regulations.gov (accessed on 5 July 2021).

17. Kheirolomoom, A.; Dayton, P.; Lum, A.; Little, E.; Paoli, E.; Zheng, H.; Ferrara, K. Acoustically-active microbubbles conjugated to liposomes: Characterization of a proposed drug delivery vehicle. J. Control. Release 2007, 118, 275-284. [CrossRef] [PubMed]

18. Bao, S.; Thrall, B.; Miller, D. Transfection of a reporter plasmid into cultured cells by sonoporation in vitro. Ultrasound Med. Biol. 1997, 23, 953-959. [CrossRef]

19. Lentacker, I.; De Cock, I.; Deckers, R.; De Smedt, S.; Moonen, C. Understanding ultrasound induced sonoporation: Definitions and underlying mechanisms. Adv. Drug Deliv. Rev. 2014, 72, 49-64. [CrossRef] [PubMed]

20. Prentice, P.; Cuschieri, A.; Dholakia, K.; Prausnitz, M.; Campbell, P. Membrane disruption by optically controlled microbubble cavitation. Nat. Phys. 2005, 1, 107-110. [CrossRef]

21. Kooiman, K.; Vos, H.; Versluis, M.; de Jong, N. Acoustic behavior of microbubbles and implications for drug delivery. Adv. Drug Deliv. Rev. 2014, 72, 28-48. [CrossRef] [PubMed]

22. Ganan-Calvo, A.; Gordillo, J. Perfectly monodisperse microbubbling by capillary flow focusing. Phys. Rev. Lett. 2001, 87, 274501-1-274501-4. [CrossRef]

23. McLaughlan, J.; Ingram, N.; Smith, P.; Harput, S.; Coletta, P.; Evans, S.; Freear, S. Increasing the sonoporation efficiency of targeted polydisperse microbubble populations using chirp excitation. IEEE Trans. Ultrason Ferroelectr. Freq. Contr. 2013, 60, 2511-2520. [CrossRef]

24. Ingram, N.; McVeigh, L.; Abou-Saleh, R.; Maynard, J.; Peyman, S.; McLaughlan, J.; Fairclough, M.; Marston, G.; Valleley, E.; Jimenez-Macias, J.; et al. Ultrasound-triggered therapeutic microbubbles enhance the efficacy of cytotoxic drugs by increasing circulation and tumor drug accumulation and limiting bioavailability and toxicity in normal tissues. Theranostics 2020, 10, 10973-10992. [CrossRef]

25. Luan, Y.; Lajoinie, G.; Gelderblom, E.; Skachkov, I.; van der Steen, A.; Vos, H.; Versluis, M.; de Jong, N. Lipid shedding from single oscillating microbubbles. Ultrasound Med. Biol. 2014, 40, 1834-1846. [CrossRef] [PubMed]

26. Luan, Y.; Faez, T.; Gelderblom, E.; Skachkov, I.; Geers, B.; Lentacker, I.; van der Steen, T.; Versluis, M.; de Jong, N. Acoustical properties of individual liposome-loaded microbubbles. Ultrasound Med. Biol. 2012, 38, 2174-2185. [CrossRef] [PubMed]

27. McLaughlan, J.; Harput, S.; Abou-Saleh, R.; Peyman, S.; Evans, S.; Freear, S. Characterisation of liposome-loaded microbubble populations for subharmonic imaging. Ultrasound Med. Biol. 2017, 43, 346-356. [CrossRef] [PubMed]

28. May, D.; Allen, J.; Ferrara, K. Dynamics and fragmentation of thick-shelled microbubbles. IEEE Trans. Ultrason Ferroelectr. Freq. Contr. 2002, 49, 1400-1410. [CrossRef]

29. Mulvana, H.; Stride, E.; Hajnal, J.; Eckersley, R. Temperature dependent behavior of ultrasound contrast agents. Ultrasound Med. Biol. 2010, 36, 925-934. [CrossRef] [PubMed]

30. de Jong, N.; Hoff, L. Ultrasound scattering properties of Albunex microspheres. Ultrasonics 1993, 31, 175-181. [CrossRef]

31. Tang, M.; Eckersley, R. Frequency and pressure dependent attenuation and scattering by microbubbles. Ultrasound Med. Biol. 2007, 33, 164-168. [CrossRef]

32. Peyman, S.; Abou-Saleh, R.; McLaughlan, J.; Ingram, N.; Johnson, B.; Critchley, K.; Freear, S.; Evans, A.; Markham, A.; Coletta, P.; et al. Expanding 3D geometry for enhanced on-chip microbubble production and single step formation of liposome modified microbubbles. Lab Chip 2012, 12, 4544-4552. [CrossRef]

33. Clegg, H.; Carpenter, T.; McLaughlan, J.; Freear, S.; Cowell, D. Using Heterogeneous Hardware for Simultaneous Diagnostic and Therapeutic Ultrasound. In Proceedings of the IEEE International Ultrasonics Symposium (IUS), Glasgow, UK, 6-9 October 2019; pp. 521-524.

34. Boni, E.; Yu, A.; Freear, S.; Jensen, J.; Tortoli, P. Ultrasound Open Platforms for Next-Generation Imaging Technique Development. IEEE Trans. Ultrason Ferroelectr. Freq. Control 2018, 65, 1078-1092. [CrossRef] [PubMed]

35. Cowell, D.; Freear, S. Quinary excitation method for pulse compression ultrasound measurements. Ultrasonics 2008, 48, 98-108. [CrossRef] [PubMed] 